\title{
Importance of Diagnosing Early Cardiac Effects in Obstructive Sleep Apnea Syndrome
} \author{
Fidan $^{5 *}$ \\ ${ }^{1}$ Department of ENT, Ahi Evran University, Turkey \\ ${ }^{2}$ Department of ENT, Ege University, Turkey \\ ${ }^{3}$ Department of Chest Diseases, Ege University, Turkey \\ ${ }^{4}$ Department of Cardiology, Manisa Merkezefendi Government Hospital, Turkey \\ ${ }^{5}$ Department of ENT, Eskisehir Yunus Emre Government Hospital, Turkey
}

Mustafa Avcu${ }^{1}$, Mehmet Metin ${ }^{1}$, Cem Bilgen ${ }^{2}$, Ozen Kacmaz Basoglu ${ }^{3}$, Ramazan Gunduz ${ }^{4}$ Alper Dilci ${ }^{5}$ and Vural

Submission: March 29, 2018; Published: April 24, 2018

*Corresponding author: Vural Fidan, Department of ENT, Eskisehir Yunus Emre Government Hospital, Turkey, Tel: 905055606842;

Email: vuralf@mynet.com

\section{Introduction}

Obstructive sleep apnea syndrome (OSAS) is characterized by sleep apneas, snoring and daytime extreme sleepiness, which are the result of recurrent upper airway collapse during sleep. Sleep apnea was firstly described by Guilleminault et al. in 1976 [1]. Prevalence of OSAS in the community is $1-5 \%$ [2]. Sleep plays an important role in the restoration of human physiological systems. Sleep-disordered breathing leads to significant clinical neurophysiologic changes. Emotional changes, impaired concentration, and memory changes are common problems in patients with OSAS [3]. Insufficient and divided sleep increases risk of accidents by causing distractibility, loss of concentration and daytime drowsiness. These patients are very important for society because of carrying the high risks of accident [4].

Many of the sleeping disorders are accompanied by a number of general effects, such as the decreasing the abilities of the home and school performance, reduction of personal opportunities and work power, psychosocial consequences, and reduced leisure and leisure time. Apart from these, many sleep disorders are accompanied by increased daytime sleepiness and increased traffic accidents (Figure 1). In OSAS patients, the risk of traffic accidents is high, which is 2-7 times higher than the normal population. Besides the increasing of traffic accidents as well as work and home accidents have increased also [5]. It should also be noted that sleeplessness is the leading cause of accidents and cause $70 \%$ of accidents. In summary, sleep disorders have increased risk of accident risk.

The prevalence of sleep disorders is influenced by many factors such as age and gender. Normal values can vary widely from population to population, and even if respiratory disturbances that are defined as a disease have a threshold value, this is not known. AHI, which includes apnea and hypopnea numbers, is a better measure of the severity of OSAS, since hypopnea and oxygen desaturation are also important parameters in these patients. A widely accepted definition is if the AHI score is $5-15$ is mild, $15-30$ is moderate, and more than 30 is defined as severe OSAS [6]. However, the degree of respiratory disturbance that can be defined as a disease is not clear. Some physiological consequences like oxyhemoglobin desaturation, cardiac arrhythmia despite a very low apnea are much more severe than those with multiple apneas and asymptomatic cases [7].

It has been shown that cardiovascular risk induced by obstructive sleep apnea is even greater in patients with AHI greater than or equal to 20 /hour, and the mortality risk is also increased in these patients.

For this reason, CPAP treatment is suitable in these cases. If $\mathrm{AHI}$ is lower than this level, surgical or non-surgical methods are introduced. In literature focusing the cardiological changes caused by obstructive sleep apnea, patients with moderate or severe OSAS are studied generally. The effects of snoring and mild OSAS to the cardiologic functions are not described well. The aim of this study is to investigate the cardiological status of patients with all obstructive sleep apnea and snoring. For this purpose, tissue Doppler imaging will be examined to enlighten the situation of early myocardial involvement in patients with sleeping disturbance.

\section{Material and Methods}

Patients who were referred to clinic due to snoring, obstructive sleep apnea symptoms were included in the study between 2007 and 2008 in Ege University ENT Department. Informed consents were obtained from all patients included in this study. Clinical evaluation consisting of routine ENT 
examination and endoscopic nasal cavity-nasopharynx and laryngologic examination and blood tests including fT3, fT4, TSH were applied to the patients. Diagnostic polysomnography recommended to the patients who were not suitable for surgical intervention and patients were referred to the Sleep Laboratuary of Department of Chest Disease of Ege University Faculty of Medicine. Anteroposterior chest graphs, arterial blood gases, pulmonary function tests were performed in this laboratuary. 130 patients were included in this study with a mean of age is 50, 55 (93 men and 27 women). All patients were referred to Ege University Faculty of Medicine, Department of Cardiology. Echocardiograms were applied. M Mod, Doppler and tissue Doppler were recorded.

\section{Parameters echo cardiographically evaluated in our study}

a. 2D Records

LVDD: (Left ventricle dimensions in diastole)

LVDS: (Left ventricle dimensions in systole)

IVS: (Interventricular septal thickness)

PW: (Posterior wall thickness)

LA: (Left atrium dimensions)

FS: Fractional shortening

RVD: (Right ventricle dimensions in diastole)

ASD: (Aortic sinus valsalva dimensions)

AAD: (Aort annular dimensions)

b. TDI (Tissue doppler imaging) Records

LSM: (Left vetricular systolic peak velocity)

LEM: (Left vetricular early peak velocity)

LAM: (Left vetricular late peak velocity)

SSM: (Interventricular septum systolic peak velocity)

SEM: (Interventricular septum early peak velocity)

SAM: (Interventricular septum late peak velocity)

RSM: (Right vetricular systolic early late peak velocity)

REM: (Right vetricular early peak velocity)

RAM: (Right vetricular late peak velocity)

c. Doppler Records

ME: (Mitral Doppler early diastolic velocity)

MA: (Mitral Doppler late diastolic velocity)

MDT: (Mitral Doppler deseleration time)

MIVRT: (Mitral interventricular relaxation time)
TE: (Tricuspid Doppler early diastolic velocity)

TA: (Tricuspid Doppler early diastolic velocity)

TDT: (Tricuspid Doppler deseleration time)

PAT: (Pulmonary acceleration time)

d. TAPSE (Tricuspid annular plane systolic excursion)

i. Cardiac patient evaluation form used in our study:

\begin{tabular}{|c|}
\hline Echocardiography Form \\
\hline Name Surname : Age: Protocol Nr: Gender: \\
AHI: \\
Risk Factors :
\end{tabular}

HT: /year DM: / year Sigara: / year, /per day HL: / year

Background: Family history: Drugs Used

CPAP Treatment: Physical examination: Arterial tension: Pulse:

\section{Left Ventricle:}

2D:

LVDD: LVDS: IVS: PW: LA: EF: EDV: ESV: FS: M MODE: LVMI: Mmode:

TDI:

Lateral Wall: Sm: Em: Am:

Septum: Sm: Em: Am:

DOPPLER:

Mitral .E: A: E/A: DT: IVRT

Aort: ASD: AAD:

Right Ventricle:

2D:

RA: RVS-RVD: ESV: EDV: RVEF: IVRT: IVKT: ET: PEP: TDI:

Right ventricle lateral wall: Sm: Em: Am:

DOPPLER:

Tricuspid: E: A: E/A: DT: IVRT:

Pulmonary Flow:

SPAP:

TAPSE(Tricuspid annular plane systolic excursion):

TEI Index:

The patient was randomly selected. SPSS (Statistical Package for Social Sciences) for Windows 10.0 program was used for the 


\section{Global Journal of Otolaryngology}

statistical analyzes. The results were evaluated in a confidence interval of $95 \%$ and a significance level of $p<0.05$. Ege University

\section{Results}

\section{a. Demographics}

Table 1:Number of patients according to groups, gender, AHI, age distribution.

Table 1: Number of patients according to groups, gender, $\mathrm{AHI}$, age distribution.

\begin{tabular}{|c|c|c|c|c|c|}
\hline OSAS category & Number of patients & Male & Female & Mean of AHI & Mean of age \\
\hline Snoring & $31(23.8 \%)$ & $19(14.6 \%)$ & $12(9.2 \%)$ & $2.300+-1.6$ & $47.61+-10.1$ \\
\hline Mild OSAS & $31(23.8 \%)$ & $20(15.4 \%)$ & $11(8.4 \%)$ & $9.313+-2.9$ & $52.32+-9.3$ \\
\hline Moderate OSAS & $33(25.4 \%)$ & $29(22.3 \%)$ & $4(3.1)$ & $21.497+-4.1$ & $49.97+-10$ \\
\hline Severe OSAS & $35(26.9 \%)$ & $25(19.2 \%)$ & $10(7.8 \%)$ & $57.046+-15.7$ & $52.11+-11.3$ \\
\hline Total & $130(100 \%)$ & $93(71.5 \%)$ & $37(28.5 \%)$ & $23.585+-23.1$ & $50.55+-10.3$ \\
\hline
\end{tabular}

Table 2: Distribution of cardiac risk factor results according to the groups.

Table 2: Distribution of cardiac risk factor results according to the groups.

\begin{tabular}{|c|c|c|c|c|c|c|}
\hline \multicolumn{7}{|c|}{ Results of cardiac risk factors (hypertension, diabetes mellitus, smoking, heart failure, obesity, hyperlipidemia) } \\
\hline & 0 & 1 & 2 & 3 & 4 & Total \\
\hline Snoring & $7(5.38 \%)$ & $16(12.3 \%)$ & $4(3.07 \%)$ & $1(0.76 \%)$ & $3(2.3 \%)$ & 31 \\
\hline Mild OSAS & $5(3.84 \%)$ & $9(6.92 \%)$ & $6(4.61 \%)$ & $10(7.73 \%)$ & $1(0.76 \%)$ & 31 \\
\hline Moderate OSAS & $8(6.17 \%)$ & $12(9.23 \%)$ & $6(4.61 \%)$ & $4(3.07 \%)$ & $3(2.3 \%)$ & 33 \\
\hline Severe OSAS & $6(4.61 \%)$ & $19(14.61 \%)$ & $5(3.84 \%)$ & $5(3.84 \%)$ & 0 & 35 \\
\hline Total & $26(20 \%)$ & $56(43,1 \%)$ & $21(16,2 \%)$ & $20(15,4 \%)$ & $7(5,4 \%)$ & 130 \\
\hline
\end{tabular}

Table 3: BMI (body mass index) results according to groups according to minimum, maximum, mean levels.

Table 3: BMI (body mass index) results according to groups according to minimum, maximum, mean levels.

\begin{tabular}{|c|c|c|c|c|c|}
\hline \multicolumn{7}{|c|}{ Body mass index } \\
\hline & Normal & Mild obesity & Moderate obesity & Severe obesity & Mean \\
\hline Snoring & 4 & 19 & 8 & 0 & 0 \\
\hline Mild OSAS & 6 & 12 & 13 & 1 & $29,4+-3.8$ \\
\hline Moderate OSAS & 1 & 21 & 10 & $13+-4.4$ & $29,815+-4.2$ \\
\hline Severe OSAS & 1 & 13 & 20 & $2,1,5 \%$ & $29,657+-4$ \\
\hline Total & $12,9,2 \%$ & $65,50 \%$ & $51,39,2 \%$ & +-4.2 \\
\hline
\end{tabular}

Table 4: Distribution of cardiac risk factors according to background and family history

Table 4: Distribution of cardiac risk factors according to background and family history.

\begin{tabular}{|c|c|c|c|c|c|}
\hline \multirow{2}{*}{} & \multicolumn{2}{|c|}{ Cardiac risk factor in background } & \multicolumn{2}{c|}{ Cardiac risk factor in family history } & \multirow{2}{*}{ Total } \\
\cline { 2 - 5 } & + & - & + & - & $14(10.7 \%)$ \\
\hline Snoring & $10(7.7 \%)$ & $21(16.1 \%)$ & $17(13 \%)$ & $20(15.4 \%)$ & 31 \\
\hline Mild OSAS & $10(7.7 \%)$ & $21(16.1 \%)$ & $11(8.5 \%)$ & $22(17 \%)$ & 31 \\
\hline Moderate OSAS & $10(7.7 \%)$ & $23(17.7 \%)$ & $11(8.5 \%)$ & $24(18.4 \%)$ & 33 \\
\hline Severe OSAS & $9(6.9 \%)$ & $26(20 \%)$ & $11(8.5 \%)$ & $80(61.5 \%)$ & 35 \\
\hline Total & $39(30 \%)$ & $91(\% 70 \%)$ & $50(\% 38.5 \%)$ & 130 \\
\hline
\end{tabular}

b. Echocardiographic results

i. General measurements: No statistically significant difference was found between groups in 2D measurement. ii. Doppler echocardiography data: Table 5: Doppler echocardiography data. A statistically significant difference was found in MA wave between the moderate and severe OSAS 


\section{Global Journal of Otolaryngology}

Table 5: Doppler echocardiography data. A statistically significant difference was found in MA wave between the moderate and severe OSAS.

\begin{tabular}{|c|c|c|c|c|c|c|c|}
\hline $\begin{array}{c}\text { Doppler echo } \\
\text { mean datas }\end{array}$ & $\begin{array}{c}\text { Normal values } \\
\mathbf{( r e f : ~ 4 2 , 4 3 )}\end{array}$ & Snoring, $\mathbf{n}: \mathbf{3 1}$ & $\begin{array}{c}\text { Mild OSAS, } \\
\mathbf{n}: \mathbf{3 1}\end{array}$ & $\begin{array}{c}\text { Moderate } \\
\text { OSAS, } \mathbf{n}: \mathbf{3 3}\end{array}$ & $\begin{array}{c}\text { Severe0SAS, } \\
\mathbf{n}: \mathbf{3 5}\end{array}$ & Total, n:130 & $\begin{array}{c}\text { Statistically } \\
\text { significance }\end{array}$ \\
\hline ME & $0,85+-0,15 \mathrm{msn}$ & 0,7555 & 0,7036 & 0,6795 & 0,7610 & 0,7254 & - \\
\hline MA & $0,55+-0,15 \mathrm{msn}$ & 0,6919 & 0,6976 & 0,6648 & 0,7887 & 0,7123 & + \\
\hline MDT & $200+-32 \mathrm{msn}$ & 210,74 & 216,61 & 222,06 & 221,14 & 217,82 & - \\
\hline MIVRT & $70-90 \mathrm{msn}$ & 98,39 & 99,68 & 101,21 & 101,43 & 100,23 & - \\
\hline TE & $0,61+-0,13$ & 0,58 & 0,576 & 0,5821 & 0,6414 & 0,5961 & - \\
\hline TA & $0,49+-0,1$ & 0,5225 & 0,5342 & 0,5461 & 0,5532 & 0,5402 & - \\
\hline TDT & $212+-12$ & 214,68 & 245,84 & 221,97 & 246,29 & 232,47 & - \\
\hline PAT & $>90 \mathrm{msn}$ & 111,95 & 105,02 & 107,17 & 99,68 & 105,78 & - \\
\hline TAPSE & $>14$ & 28,23 & 28,44 & 29,82 & 28,51 & 28,76 & - \\
\hline
\end{tabular}

iii. Tissue Doppler (TDI) data: Table 6: A statistically significant difference was found in the SEM group between snoring and moderate OSAS, between snoring and severe OSAS in the RSM group, and between all groups in the RAM group.

Table 6: A statistically significant difference was found in the SEM group between snoring and moderate OSAS, between snoring and severe OSAS in the RSM group, and between all groups in the RAM group.

\begin{tabular}{|c|c|c|c|c|c|c|c|}
\hline \multicolumn{2}{|c|}{ TDI mean datas } & \multirow[b]{2}{*}{ Snoring, n:31 } & \multirow[b]{2}{*}{$\begin{array}{l}\text { Mild OSAS, } \\
\quad \mathrm{n}: 31\end{array}$} & \multirow[b]{2}{*}{$\begin{array}{c}\text { Moderate } \\
\text { OSAS, n:33 }\end{array}$} & \multirow[b]{2}{*}{$\begin{array}{c}\text { SevereOSAS, } \\
\text { n:35 }\end{array}$} & \multirow[b]{2}{*}{ Total, n:130 } & \multirow[b]{2}{*}{$\begin{array}{l}\text { Statistically } \\
\text { significance }\end{array}$} \\
\hline & $\begin{array}{c}\text { Normal values } \\
\text { (ref: 42) }\end{array}$ & & & & & & \\
\hline LSM & $\begin{array}{c}10,2+-2,1 \mathrm{~cm} / \\
\mathrm{sn}\end{array}$ & 8,294 & 8,781 & 8,221 & 8,374 & 8,413 & - \\
\hline LEM & $\begin{array}{c}14,9+-3,5 \mathrm{~cm} / \\
\mathrm{sn}\end{array}$ & 11,794 & 10,677 & 10,030 & 10,689 & 10,782 & - \\
\hline LAM & $6,6+-2,4 \mathrm{~cm} / \mathrm{sn}$ & 10,023 & 10,396 & 9,482 & 10,668 & 10,148 & - \\
\hline SSM & $7,8+-1,1 \mathrm{~cm} / \mathrm{sn}$ & 6,647 & 6,586 & 6,686 & 7,074 & 6,758 & - \\
\hline SEM & $\begin{array}{c}11,2+-1,9 \mathrm{~cm} / \\
\mathrm{sn}\end{array}$ & 9,213 & 7,942 & 7,473 & 8,654 & 8,318 & + \\
\hline SAM & $7,8+-2 \mathrm{~cm} / \mathrm{sn}$ & 8,823 & 9,803 & 9,535 & 9,511 & 9,423 & - \\
\hline RSM & $\begin{array}{c}12,2+-2,6 \mathrm{~cm} / \\
\mathrm{sn}\end{array}$ & 12,974 & 13,042 & 13,585 & 14,723 & 13,616 & + \\
\hline REM & $\begin{array}{c}12,9+-3,5 \mathrm{~cm} / \\
\mathrm{sn}\end{array}$ & 11,923 & 12,319 & 11,294 & 12,020 & 11,884 & - \\
\hline RAM & $\begin{array}{c}11,6+-4,1 \mathrm{~cm} / \\
\mathrm{sn}\end{array}$ & $\begin{array}{c}15,129 \\
(p: 0,036)\end{array}$ & $\begin{array}{c}14,135 \\
\text { (p:0.001) }\end{array}$ & $\begin{array}{c}15,124 \\
\text { (p:0,031) }\end{array}$ & 17,957 & 15,652 & + \\
\hline
\end{tabular}

c. Statistics: Table 7: Comparison of severity of OSAS and body mass index. Table 8: There was statistically significant difference in tissue doppler records of interventricular septum in both groups.

Table 7: Comparison of severity of OSAS and body mass index

\begin{tabular}{|c|c|c|c|c|c|}
\hline & & \multicolumn{3}{|c|}{ Body mass index } & \multirow{2}{*}{ Total } \\
\hline & & Normal & Mild obesity & Obesity & \\
\hline \multirow{4}{*}{ OSAS severity } & Snoring & 4 & 19 & 8 & 31 \\
\hline & Mild OSAS & 6 & 12 & 13 & 31 \\
\hline & Moderate OSAS & 1 & 21 & 11 & 33 \\
\hline & Severe OSAS & 1 & 13 & 21 & 35 \\
\hline \multicolumn{2}{|c|}{ Total } & 12 & 65 & 53 & 130 \\
\hline
\end{tabular}

Statistically significant in chi-square tests (Pearson Chi-Square, Likelihood Ratio, Linear-by-Linear Association). (0,013-0,013-0,004) 


\section{Global Journal of Otolaryngology}

Table 8: There was statistically significant difference in tissue doppler records of interventricular septum in both groups.

\begin{tabular}{|c|c|c|c|c|c|}
\hline \multicolumn{5}{|c|}{ Statistically significance } \\
\hline OSAS & LEM/LAM & REM/RAM & SEM/SAM & ME/MA & TE/TA \\
\hline Snoring & - & - & + & - & - \\
\hline Mild OSAS & - & - & + & - & - \\
\hline Moderate OSAS & - & - & + & - & - \\
\hline Severe OSAS & - & - & + & - \\
\hline
\end{tabular}

\section{Discussion}

In almost all cases, cardiac involvement is evident in patients with OSAS. However, diagnosing of this situation is not always possible, especially in the early stages of OSAS and conventional methods. Tissue Doppler examination (TDI) is an echocardiography technique that provides important information about myocardial function. This method, with conventional tests; can give important information about heartrelated myocardial dysfunction in normal individuals also [8]. Normally, blood pressure and heart rate are reduced, the cardiac output is unchanged or decreased in sleep. The blood pressure rises, becomes irregular, but still maintains levels according to the levels of wakefulness during the REM period of sleep. These hemodynamic changes in sleep are caused by fluctuations in the autonomic nervous system [9].

Large fluctuations in systemic and pulmonary arterial blood pressures during obstructive apneas were first described by Coccogna et al. [10]. Blood pressure and heart rate decrease in early phase of apnea. In the second half of the apnea oxygen saturation decreases, pleural pressure fluctuations increase, heart rate and blood pressure rise. In the third phase of apnea, when apnea is terminated and «arousal» occurs, the heart rate further increases and blood pressure rises to the summit [11]. Hypoxia affects the blood pressure due to many mechanisms [11]. The local vascular effect of severe hypoxia tends to reduce arterial blood pressure by vasodilation. Early mechanisms in this regard are thought to be via by vasoactive substances such as nitric oxide (NO), adenosine and eicosanoids released from endothelium [11]. Acute hypoxaemia, on the other hand, leads to reflex vasoconstriction, increased heart rate and increased autonomic nervous system activity [12]

Blood pressure elevation at the end of apnea is associated with the depth of hypoxia that is present during apnea. In REM sleep, there is a higher baseline blood pressure value and a more severe hemodynamic response in response to obstructive apnea. This is explained by higher sympathetic nervous system activity during REM sleep [11]. Some neuro humoral changes have been described to explain the short and long term effects of OSAS on the cardiovascular system. The sympathetic system activity, which is the main cause of apnea-associated blood pressure elevations, increases during wakefulness not only during sleep. This distinctive sympathetic activity recovers with CPAP therapy [13]. Atrial natriuretic peptide (ANP) release increases during apnea [14]. The diuresis in the apnea can be explained by these
ANP elevations. Other cardiovascular modulators that concern the pathophysiology of OSAS include eicosanoids and endothelin [15].

Vascular endothelial dysfunction and structural vascular changes are the first mechanisms to explain systemic hypertension [16]. Many vasoactive substances such as prostanoid, endothelin, nitric oxide (NO) from vascular endothelium are released. Vascular permeability, endothelial cell proliferation, angiogenesis and vascular tone are changed due to acute release of these substances. After an infusion of angiotensin-2 to the brachial artery, patients with normotensive OSAS showed an increased vasoconstrictor response compared to the control group [17]. It suggests that endothelial damage is present in these cases. Systemic hypertension and its consequences increase cardiovascular system mortality in OSAS patients [18]. The prevalence of OSAS in the hypertensive population was high $(20-30 \%)$ in various studies $[19,20]$.

Periodic blood pressure increases due to apneas during sleep in patients with OSAS affect the normal daily rhythm of the systemic blood pressure. According to this rhythm, 3 different patterns are observed in patients with OSAS; normotensive cases experiencing physiological blood pressure reduction in the nights, hypertensive cases with nocturnal hypertension and hypertensive cases with high blood pressure all day [21]. Studies have suggested that sudden increases in pulmonary artery pressure are common in patients with OSAS, but about $20 \%$ of them are proven pulmonary hypertension. The prevalence of pulmonary hypertension (41\%) was increased in patients with OSAS whose pulmonary functions were also impaired [22]. There are various changes in heart rate in each apnea cycle. While heart rate increases in non-REM sleep, it tends to decrease in REM sleep [23].

A sudden tachycardia occurs when the 3rd cycle of apnea is terminated by «arousal» or hyperventilation. This typical pattern is considered exaggerated in the respiratory sinus arrhythmia seen in healthy subjects. Bonsignore et al. had done the largest study on this subject [23]. Bradycardia develops in REM sleep, especially in young male cases. Bradycardia, 1st and 2nd degree atrioventricular and sinoatrial blocks were observed during apneas [24]. There is a serious correlation between severe OSAS, morbid obesity, REM sleep, severe hypoxia and bradycardia formation $[25,26]$. These arrhythmias improve with CPAP therapy in most patients (88\%) [24]. Tachyarrhythmias are also common in OSAS cases. The prevalence of premature ventricular 
pulsation increases in direct proportion to the degree of AHI and nocturnal desaturation [24-27]. In respiratory disorders during sleep, the risk of atrial fibrillation is 2.8 times more [28].

Cheyne-Stokes respiration and central sleep apnea syndrome are the most common cases of heart failure [29]. This respiratory pattern leads to sleep divisions, deterioration of sleep architecture and excessive daytime sleepiness. This pattern also increases mortality in patients with congestive heart failure $[29,30]$. In the literature; pharmacologic treatment of congestive heart failure includes oxygen, theophylline, and nasal CPAP. New studies have shown that there may be right ventricular dysfunction in OSAS [31]. This disorder is associated with AHI and nocturnal hypoxia unlike it is independent from age, body mass index and pulmonary function parameters. With six to twenty-four months of CPAP therapy, the right ventricular ejection fraction increases from $30 \%$ to $39 \%$ [31].

In a study by Kawanishi et al., 50 patients underwent polysomnography and echocardiography. Tissue Doppler measurements showed changes in myocardial and mitral valve in OSAS patients compared to non-OSAS patients, but the entire systolic function did not differ from each group [32]. In a study done by Okuda and his colleagues, 30 patients who underwent echocardiography during the dobutamine stress test and tissue Doppler records were taken to investigate the effects of hypoxia on the myocardium. Tissue Doppler recordings were taken for the left heart, especially during the dobutamine stress test in the early diastolic wave, while OSAS grade was less in the heavier group [33].

Tavil and his colleagues conducted a study on 77 patients with 20 OSAS, $20 \mathrm{HT}, 16$ OSAS and HT and 21 control groups in order to investigate the presence and influence of the OSAS regardless of hypertension. In addition to echocardiographic measurements, Tissue Doppler studies were performed. It has been reported that myocardial performance index, which is calculated by tissue doppler data in OSAS patients with systolic and diastolic functions in both ventricles, is a parameter that may show the cardiac effects of OSAS, especially right ventricular pathology [34].

In the study done by Dursunoglu and colleagues, 67 patients who were treated with CPAP for 6 months were found to have significantly decreased left ventricular posterior wall (LVPW) and interventricular septum (IVS) thickness compared with previous values. A decrease in the calculated myocardial performance index was found after conventional and tissue Doppler examination [13]. In study performed by Kaşıkçığlu and his colleagues, it was emphasized that tissue Doppler imaging may represent an early myocardial abnormality despite a protected global duty [14]. In a study by Kim and colleagues, main aim is to investigate a tissue doppler parameter that could be used for left ventricle in OSAS. Of these, 62 patients were included in the study, 18 of them mild and moderate, 24 are severe, and 20 are controls. In the severe OSAS group, early diastolic dysregulation decreased related to left ventricle. At the same time, diabetes mellitus, hypertension, body mass index were not affected and it was reported that the most reliable parameters were early diastolic wave of left ventricle [35].

In the study by Akar et al., changes in left ventricular function were investigated as a result of CPAP therapy. A total of 46 patients were evaluated consists of a control group of 18 patients with 28 moderate and severe OSAS. According to the control group before CPAP, systolic and diastolic dysfunction values determined by tissue doppler examination were found to be improved after treatment [36]. There are very significant relationships between OSAS and cardiac pathologies. OSAS is known to be a progressive disease, often linked to patient-related characteristics. The cardiac pathology that starts in this period can manifest itself clinically in the later stages of the disease. In fact, some clinical situations cost the patient's life. Even in simple snoring patients within the spectrum of OSAS disease, cardiac involvement begins subclinically. There are tissue doppler studies in OSAS patients diagnosed by polisomnography in the literature recently. These studies included only advanced-stage OSAS patients with subclinical cardiac involvement findings [3136].

However, studies in the literature have evaluated advanced stage patients. Simple snoring and mild OSAS patients that can be considered as early stage are not included in these studies. OSAS has been studied on specific (moderate - severe) groups. In our study, patients with sleep disorders with polisomnography were included. In literature, control group data and patient group data were compared. In addition to the criteria mentioned above, it may be appropriate for evaluation with echocardiographic data in the studies. There were no statistically significant differences in terms of number of patients, gender, AHI, age, history, and family history of each of the four randomized groups of our study. This allowed us to work in a more homogeneous patient group in cardiac terms. However, there was a significant difference between the group of OSAS and BMI.

There was no statistically significant difference between conventional echocardiographic examinations and measurements (2D, Doppler) except for mitral valve late diastolic (MA) wave. This finding showed that pulmonary vascular resistance in the early stages of the illness was lower than expected. Tissue Doppler (TDI) data; SEM value between snoring and moderate OSAS; RSM value between snoring and heavy OSAS; a statistically significant difference in RAM value was found among all groups. A statistically significant difference was found in favor of diastolic dysfunction, especially in the interventricular septum TDI results, when each group was compared. In order to explain about diastolic dysfunction, the ratio of TDI data to early diastolic and late diastolic is used. There was a significant difference between all groups in the ratio of interventricular septum (SEM / SAM). Patients were divided into groups according to the cardiac risk factors and gender. 


\section{Global Journal of Otolaryngology}

These groups were taken into separate statistical studies. 2 and less risk patients (n: 103), 3 and more risk patients (n: 27), male patients (n: 93) and female patients (n: 37) Significant differences were noted in the records of the right ventricle.

\section{Conclusion}

The aim of this study was to investigate the presence of myocardial involvement by tissue doppler technique in patients with sleep apnea syndrome who were normally identified on standard echocardiography. In this study, we tried to determine whether myocardial abnormality was present in patients with snoring and OSAS in spite of protected global cardiac functions. In our study, tissue doppler data, which vary with OSAS grade, especially regarding the septum and right ventricular wall as cardiac, and causing the differences between the groups, have been determined.

Although there were no statistically significant differences between the groups in our study, the necessity of wider studies with this idea was accepted, especially if the tissue doppler parameters of patients with AHI were close to that of patients with advanced OSAS patients, it was accepted as close followers and advanced patients and it was decided that the treatment of these treatments would be appropriate.

\section{References}

1. Guilleminault C, Tilkian A, Dement WC (1976) The sleep apnea syndrome. Ann Rev Med 27: 465-484.

2. Duong-Quy S, Dang Thi Mai K, Tran Van N, Nguyen Xuan Bich H, HuaHuy T, et al. (2018) Study about the prevalence of the obstructive sleep apnoea syndrome in Vietnam. Rev Mal Respir 35(1): 14-24.

3. Croft CB, Pringle MB (1997) Snoring and sleep apnea. Scott Brown Otolaryngology Oxford 23: 234-239.

4. Dement WC, Mitler MM (1993) It's time to wake up to the importance of sleep disorders. JAMA 269(12): 1548-1550.

5. Frey JG (2005) Obstructive sleep apnea and motor vehicle accident Rev Med Suisse 8: 1561-1562.

6. Friedman M, Ibrahim H, Bass L (2002) Clinical Staging for SleepDisordered Breathing. Otolaryngol Head Neck Surg 127(1): 13-21.

7. Roux F, Ambrosio CD, Mohsenin V (2000) Sleep-related Breathing disorders and Cardiovascular Disease. Am J Med 108(5): 396-402.

8. Nagueh SF, Bachinski LL, Meyer D, Hill R, Zoghbi WA, et al. (2001) Tissue Doppler imaging consistently detects myocardial abnormalities in patients with hypertrophic cardiomyopathy and provides a nove means for an early diagnosis before and independently of hypertrophy. Circulation 104: 128-130.

9. Somers VK, Dyken ME, Mark AL, Abboud FM (1993) Sympathetic-nerve activity during sleep in normal subjects. N Engl J Med 328(5): 303-307.

10. Coccagna G, Mantovani M, Brignani F, Parchi C, Lugaresi E (1972) Continuous recording of the pulmonary and systemic arterial pressure during sleep in syndromes of hypersomnia with periodic breathing. Bull Physiopathol Respir (Nancy) 8(5): 1159-1172.

11. Scharf SM (1994) Influence of sleep state and breathing on cardiovascular function. In: Saunders NA, Sullivan CF, editors. Sleep and Breathing. New York: Marcel Decker pp.221-39.

12. Devito F, Zito A, Dragonieri S, Carratù P, Quaranta VN, et al. (2017) Evaluation of endothelial function and cardiovascular risk in non- obese patients with slight degree of obstructive sleep apnea syndrome. Monaldi Arch Chest Dis 87(3): 822

13. Dursunoglu N, Dursunoglu D, Ozkurt S, Kuru O, Gür S, et al. (2007) Effects of CPAP on left ventricular structure and myocardial performance index in male patients with obstructive sleep apnoea. Sleep Med 8(1): 51-59.

14. Kasikcioglu HA, Karasulu L, Tartan Z, Kasikcioglu E, Cuhadaroglu C, et al. (2007) Occult cardiac dysfunction in patients with obstructive sleep apnea syndrome revealed by tissue Doppler imaging. Int J Cardiol 118(2): 203-205

15. Dursunoglu N, Dursunoglu D, Özkurt S, Tanriverdi H, Evrengül H, et al. (2006) Severe sleep apnea syndrome diagnosed with acute myocardial infarction. Asian Cardiovasc Thorac Ann 15(1): e3-6.

16. Carlson JT, Rangemark C, Hedner JA (1996) Attenuated endotheliumdependent vascular relaxation in patients with sleep apnoae. J Hypertens 14(5): 577-584.

17. Kraiczi H, Magga J, Sun XY, Ruskoaho H, Zhao X, et al. (1999) Hypoxic pressor response, cardiac size, and natriuretic peptides are modified by long-term intermittent hypoxia. J Appl Physiol 87(6): 2025-2031.

18. Partinen M, Jamieson A, Guilleminault C (1988) Long-term outcome for obstructive sleep apnea syndrome patients, mortality. Chest 94(6): $1200-1204$

19. Lavie P, Ben Yosef R, Rubin AE (1984) Prevalence of sleep apnea syndrome among patients with essential hypertension. Am Heart 108(2): 373-376.

20. Weitzenblum E, Krieger J, Apprill M, Vallée E, Ehrhart M, et al. (1988) Daytime pulmonary hypertension in patients with obstructive sleep apnea. Am Rev Respir Dis 138(2): 345-349.

21. Xie C, Zhu R, Tian Y, Wang K (2017) Association of obstructive sleep apnoea with the risk of vascular outcomes and all-cause mortality: a meta-analysis. BMJ Open 7(12).

22. Sajkov D, Cowie RJ, Thornton AT (1994) Pulmonary hypertension and hypoxemia in obstructive sleep apnea syndrome. Am J Respir Crit Care Med 149: 416-422.

23. Bonsignore MR, Marrone O, Insalaco C, Bonsignore C (1994) The cardiovascular effects of obstructive sleep apneas: analysis of pathogenetic mechanisms. Eur Respir J 7(4): 786-805.

24. Becker H, Brandenburg U, Peter JH, von Wichert P (1995) Reversal of sinus arrest and atrioventricular conduction block in patients with sleep apnea during nasal continuous positive airway pressure. Am J Respir Crit Care Med 151(1): 215-218.

25. Palomaki H, Partinen M, Erkinjuntti I, Kaste M (1992) Snoring, sleep apnea syndrome and stroke. Neurology 42: 75-82.

26. Tilkian AG, Guilleminault C, Schroeder JS, Lehrman KL, Simmons FB, et al. (1977) Sleep-induced apnea syndrome: prevalence of cardiac arrhythmias and their reversal after tracheostomy. Am J Med 63(3): 348-358.

27. Hoffstein V, Mateika S (1994) Cardiac arrhythmias, snoring, and sleep apnea. Chest 106(2): 466-471.

28. Mooe T, Gullsby S, Rabben T, Erksson P (1996) Sleep disordered breathing: a novel predictor of atrial fibrillation after coronary bypass surgery. Coron Artery Dis 7(6): 475-478.

29. Findley LJ, Zwillich CW, Ancoli-Israel S, Kripke D, Tisi G, et al. (1985) Cheyne-Stokes breathing during sleep in patients with left ventricular heart failure. South Med J 78(1): 11-15.

30. Javaheri S, Parker TJ, Wexler L, Michaels SE, Stanberry E, et al. (1995) Occult sleep disordered breathing in stable congestive heart failure. Ann Intern Med 122: 487-492. 


\section{Global Journal of Otolaryngology}

31. Nahmias J, Lao R, Karetzky M (1996) Right ventricular dysfunction in obstructive sleep apnea: reversal with nasal continuous positive airway pressure. Eur Respir J 9: 945-951.

32. Kawanishi Y, Ito T, Okuda N, Emura N, Hayashi T, et al. (2007) Alteration of myocardial characteristics and function in patients with obstructive sleep apnea. Int J Cardiol.

33. Okuda N, Ito T, Emura N, Suwa M, Hayashi T, et al. (2007) Depressed myocardial contractile reserve in patients with obstructive sleep apnea assessed by tissue Doppler imaging with dobutamine stress echocardiography. Chest 131(4): 1082-1089.

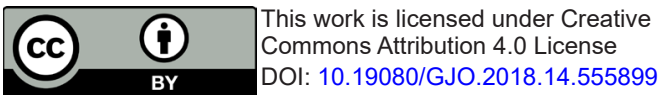

34. Tavil Y, Kanbay A, Sen N, Ciftçi TU, Abaci A, et al. (2007) Comparison of right ventricular functions by tissue Doppler imaging in patients with obstructive sleep apnea syndrome with or without hypertension. Int J Cardiovasc Imaging 23(4): 469-477.

35. Kim SH, Cho GY, Shin C, Lim HE, Kim YH, et al. (2008) Impact of obstructive sleep apnea on left ventricular diastolic function. Am J Cardiol 101(11): 1663-1668.

36. Akar Bayram N, Ciftci B, Durmaz T, Keles T, Yeter E, et al. (2009) Effects of continuous positive airway pressure therapy on left ventricular function assesed by tissue doppler imaging in patients with obstructive sleep apnoea syndrome. Eur J Echocardiogr 10(3): 376-382.

Your next submission with Juniper Publishers will reach you the below assets

- Quality Editorial service

- Swift Peer Review

- Reprints availability

- E-prints Service

- Manuscript Podcast for convenient understanding

- Global attainment for your research

- Manuscript accessibility in different formats

( Pdf, E-pub, Full Text, Audio)

- Unceasing customer service

Track the below URL for one-step submission https://juniperpublishers.com/online-submission.php 